5. Johannes A, Kredel M, Zollhoefer B, Schlegel N, Von Kirschbaum C, Brederlau J, et al. Influence of apneic oxygenation and minimal tidal volumes on ventilator-associated lung injury. Minerva Anestesiol 2014;80:526-536.

Copyright (C) 2019 by the American Thoracic Society

\section{a Reply to Kredel et al.}

\section{From the Authors:}

We appreciate the editorial by Fan (1) and the letter by Kredel and colleagues regarding our recent publication (2). Both compare the near-apneic ventilation strategy we applied, associated with high-flow veno-venous extracorporeal membrane oxygenation (ECMO), with near-apneic strategies applied in association with low-flow extracorporeal $\mathrm{CO}_{2}$ removal systems $\left(\mathrm{ECCO}_{2} \mathrm{R}\right)$. We think this comparison overlooks a fundamental difference. In the original experience in patients with acute respiratory distress syndrome (ARDS) reported by Gattinoni and coworkers (3), intermittent sighs to peak airway pressures of $35-45 \mathrm{~cm} \mathrm{H}_{2} \mathrm{O}$ and high positive end-expiratory pressure (PEEP) levels from 15 to $25 \mathrm{~cm} \mathrm{H}_{2} \mathrm{O}$ were applied. In Johannes and colleagues' study (4), PEEP levels above $20 \mathrm{~cm} \mathrm{H}_{2} \mathrm{O}$ were used after a recruitment maneuver in an experimental model of ARDS. In contrast, our near-apneic strategy kept PEEP at $10 \mathrm{~cm} \mathrm{H}_{2} \mathrm{O}$ and maximal airway pressures at $20 \mathrm{~cm} \mathrm{H}_{2} \mathrm{O}$. Although the decreases in $\dot{\mathrm{V}}$ E were of similar magnitude to our study, airway pressures differ markedly. As $\mathrm{ECCO}_{2} \mathrm{R}$ does not contribute to oxygenation, very high airway pressures have to be applied in severe ARDS to maintain oxygenation, so that static stress and strain remain high, and eventually right ventricular function and hemodynamics may be compromised. This potential risk has become more apparent after the negative results of the OSCILLATE (Oscillation for ARDS Treated Early) and ART (Alveolar Recruitment for Acute Respiratory Distress Syndrome Trial) trials $(5,6)$. In contrast, in our study, we could keep significantly lower mean and driving airway pressures, avoiding both static and dynamic stress and strain. We believe this is the fundamental reason why our results differ from those of Johannes and colleagues (4), who found no positive effect of decreasing VT to 3 or even $0 \mathrm{ml} / \mathrm{kg}$ on lung tissue inflammation. In fact, we have recently presented in abstract form the results of a study evaluating 3 different airway pressures (low: PEEP $0 \mathrm{~cm}$ $\mathrm{H}_{2} \mathrm{O}$-peak inspiratory pressure [PIP] $10 \mathrm{~cm} \mathrm{H}_{2} \mathrm{O}$; moderate: PEEP $10 \mathrm{~cm} \mathrm{H}_{2} \mathrm{O}$-PIP $20 \mathrm{~cm} \mathrm{H}_{2} \mathrm{O}$; high: PEEP $20 \mathrm{~cm} \mathrm{H}_{2} \mathrm{O}-\mathrm{PIP}$ $30 \mathrm{~cm} \mathrm{H}_{2} \mathrm{O}$ ) applied during a near-apneic protocol in the same model of ARDS supported by venovenous ECMO (7). We found that low and high airway pressures were associated with increased lung water and higher histologic scores, respectively, compared with a near-apneic protocol using moderate airway pressures

This article is open access and distributed under the terms of the Creative Commons Attribution Non-Commercial No Derivatives License 4.0

(http://creativecommons.org/licenses/by-nc-nd/4.0/). For commercial usage and reprints, please contact Diane Gern (dgern@thoracic.org).

Originally Published in Press as DOI: 10.1164/rccm.201812-2258LE on January 4, 2019 (which is the same protocol used in the near-apneic group of the present study).

The issue of mechanical ventilation during ECMO has been poorly studied. Most studies published up to now have been surveys (8), observational descriptive studies (9), and noncontrolled studies to assess feasibility or physiologic effects of certain interventions (10). Our study is one of the first efforts to compare different ventilatory strategies during ECMO in a controlled design. The study was planned as a proof of concept regarding the value of resting the lungs by minimizing the energy imposed. We believe the results provide significant evidence in favor of the lung rest concept. The fact that not all the measured variables were modified by the ventilator strategy is completely expected in a 24-hour experimental model comparing clinically relevant strategies. However, histologic lung injury, which is a major component of ARDS, was clearly improved by near-apneic ventilation.

In the recently published EOLIA, the largest randomized clinical trial to date on venovenous ECMO for severe ARDS, patients assigned to the ECMO group had a reduction in their mechanical power by 2.5 times in relation to the control group (conventional protective protocol) (11). Although this is a significant reduction, if our experimental near-apneic protocol would have been in place, the reduction in mechanical power compared with the control group would have been in the order of 18 times. It is uncertain whether this would have resulted in better clinical outcomes; however, based on our data, we think this should be assessed in future trials.

We fully agree with Fan (1) and Kredel and colleagues (2) that several uncertainties remain about the role of prone position, spontaneous breathing, or specific ventilatory variables to achieve the ideal lung rest. While we wait for clinical studies in this area, we will continue addressing these questions via an experimental approach.

The story of prone position has taught us that we should not give up sound concepts only because they are old or we have not been able to find their place. Instead, we must learn from our mistakes, refresh the valuable old concepts with new perspectives, and challenge our current approaches. We think that our study, despite all the limitations of an experimental design, is a significant step in that direction.

Author disclosures are available with the text of this letter at www.atsjournals.org.

Joaquin Araos, D.V.M., Ph.D. Alejandro Bruhn, M.D., Ph.D.*

Pontificia Universidad Católica de Chile

Santiago, Chile

ORCID ID: 0000-0001-8034-1937 (A.B.).

${ }^{*}$ Corresponding author (e-mail: alejandrobruhn@gmail.com).

\section{References}

1. Fan E. "There is nothing new except what has been forgotten": the story of mechanical ventilation during extracorporeal support. Am $J$ Respir Crit Care Med [online ahead of print] 03 Oct 2018; DOI: 10.1164/rccm.201809-1728ED. 
2. Araos J, Alegria L, Garcia P, Cruces P, Soto D, Erranz B, et al. Nearapneic ventilation decreases lung injury and fibroproliferation in an ARDS model with ECMO. Am J Respir Crit Care Med [online ahead of print] 14 Sep 2018; DOI: 10.1164/rccm.201805-0869OC.

3. Gattinoni L, Pesenti A, Mascheroni D, Marcolin R, Fumagalli R, Rossi F, et al. Low-frequency positive-pressure ventilation with extracorporeal CO2 removal in severe acute respiratory failure. JAMA 1986;256: 881-886.

4. Johannes A, Kredel M, Zollhoefer B, Schlegel N, Von Kirschbaum C, Brederlau J, et al. Influence of apneic oxygenation and minimal tidal volumes on ventilator-associated lung injury. Minerva Anestesiol 2014;80:526-536.

5. Ferguson ND, Cook DJ, Guyatt GH, Mehta S, Hand L, Austin P, et al.; OSCILLATE Trial Investigators; Canadian Critical Care Trials Group. High-frequency oscillation in early acute respiratory distress syndrome. N Engl J Med 2013;368:795-805.

6. Cavalcanti AB, Suzumura ÉA, Laranjeira LN, Paisani DM, Damiani LP, Guimarães HP, et al.; Writing Group for the Alveolar Recruitment for Acute Respiratory Distress Syndrome Trial (ART) Investigators. Effect of lung recruitment and titrated positive end-expiratory pressure (PEEP) vs low PEEP on mortality in patients with acute respiratory distress syndrome-a randomized clinical trial. JAMA 2017;318:1335-1345.

7. Araos J, Alegria L, Soto D, Garcia P, Garcia A, Dubo S, et al. How much airway pressure to apply while resting the lungs in severe ARDS supported with ECMO? [abstract]. Presented at ESICM LIVES 2018. October 24-28, 2018, Paris, France.

8. Marhong JD, Telesnicki T, Munshi L, Del Sorbo L, Detsky M, Fan E. Mechanical ventilation during extracorporeal membrane oxygenation: an international survey. Ann Am Thorac Soc 2014;11:956-961.

9. Schmidt M, Stewart C, Bailey M, Nieszkowska A, Kelly J, Murphy L, et al. Mechanical ventilation management during extracorporeal membrane oxygenation for acute respiratory distress syndrome: a retrospective international multicenter study. Crit Care Med 2015;43: 654-664.

10. Franchineau G, Bréchot N, Lebreton G, Hekimian G, Nieszkowska A Trouillet $\mathrm{JL}$, et al. Bedside contribution of electrical impedance tomography to setting positive end-expiratory pressure for extracorporeal membrane oxygenation-treated patients with severe acute respiratory distress syndrome. Am J Respir Crit Care Med 2017; 196:447-457.

11. Combes A, Hajage D, Capellier G, Demoule A, Lavoué S, Guervilly C et al.; EOLIA Trial Group, REVA, and ECMONet. Extracorporeal membrane oxygenation for severe acute respiratory distress syndrome. N Engl J Med 2018;378:1965-1975.

Copyright (C) 2019 by the American Thoracic Society

\section{Erratum: Loss of SMAD3 Promotes Vascular Remodeling in Pulmonary Arterial Hypertension via MRTF Disinhibition}

The article by Zabini and colleagues (1), published in the January 15,2018 , issue of the Journal, omitted mention of the project number for one of the funding sources; the relevant sentence should read: "Supported by the Erwin-Schroedinger Fellowship of the Austrian FWF Foundation (D.Z.; J3603), and grants-in-aid from the Canadian Institutes of Health Research and the Heart and Stroke Foundation of Canada (W.M.K.)."

\section{Reference}

1. Zabini D, Granton E, Hu Y, Miranda MZ, Weichelt U, Breuils Bonnet S, Bonnet S, Morrell NW, Connelly KA, Provencher S, Ghanim B, Klepetko W, Olschewski A, Kapus A, Kuebler WM. Loss of SMAD3 promotes vascular remodeling in pulmonary arterial hypertension via MRTF disinhibition. Am J Respir Crit Care Med 2018;197:244260.

Copyright (C) 2019 by the American Thoracic Society a This article is open access and distributed under the terms of the Creative Commons Attribution Non-Commercial No Derivatives License 4.0 (http:// creativecommons.org/licenses/by-nc-nd/4.0/). For commercial usage and reprints, please contact Diane Gern (dgern@thoracic.org). 